\title{
Kerry Pope
}

Toongabbie Christian College

library@tcc.nsw.edu.au

\section{Walking a Mile in Their Shoes: Empowering Learners Through A Human Library!}

\begin{abstract}
Many different events and experiences shape our lives. Everyone has their own unique story. Just like a book, the stories inside people are fascinating! When personal stories are shared with others they can become extremely powerful resources. They provide our students with a wonderful opportunity to connect with diverse members of the school community and beyond, communicate with them, build relationships, empathise, explore, understand and learn. By participating in a 'Human Library' students acquire life skills, widening their understanding of others and the world. Your school library should have one! Students are hungry for real life experiences and 'living books' inspire them!
\end{abstract}

Keywords: Human Library, diversity, community, school library, living books

\section{Introduction:}

'You truly cannot understand or criticise someone until you walk a mile in their shoes - and to do that you have to meet them and talk to them.'Author unknown

Our Human Library complements our print and digital Library collections and has added a richness to the learning taking place in our school. We need to teach our students how to respect, value and gain knowledge, understanding and insight from others. Everyone has a 'story', and we can learn so much from listening to other people's stories. Our schools and local communities are full of stories. The people around us, those who live in our cities, suburbs, towns and villages, can become 'living books'. There is a whole community of untapped resources out there! We are all part of a community. We all have a vast bank of human resources on our doorstep. Each person in our community has their own unique story. And we all have our curriculums to resource and our students to inspire!

All these 'living books' are free and just waiting for us to engage with them, give them the opportunity to share their special stories with us and encourage our students to actively engage and listen. When we listen, truly listen, to someone else's story, we begin to understand who they are in a new and different way, we hear their perspective, their interpretation, their understanding 
of the world around us and of themselves. It's a wonderful way to learn, be inspired, build empathy with others and connect with diverse members of our communities.

\section{The development of the Human Library}

The history of Human Libraries

The Human Library is an international organisation that first started in Copenhagen, Denmark, in 2000 as a 'Living Library' at the Roskilde Youth Festival, one of the largest music festivals in Europe. The Living Library was initiated to 'Stop the Violence' and conflict associated with stereotypes, stigma, prejudice and discrimination.

It was highly successful with more than 1,000 people participating. It ran for eight hours a day during the festival and featured over seventy-five different living books. Human connection was seen to be the crucial element in the success of this new and exciting initiative. The Living Library, set up at the festival in Denmark, as part of the activities offered to participants, invited people to borrow a living book for a short period of time, listen to their story and engage in a two-way conversation with them, where they could ask questions and share ideas and information. It proved to be a very effective means of promoting human rights including respect for diversity, equity and inclusion. From there the idea spread across central Europe and to the rest of the world.

\section{Human Libraries today}

Today, the Human Library organisation is active in more than 85 countries worldwide and aims to address people's prejudices by providing the opportunity for them to talk to those they would not normally meet. The first permanent Human Library in Australia was established in Lismore, NSW in 2006. Regular sessions were held in the Lismore Public Library and over time, Lismore City Council considered it to be "a proven, safe and low-cost tool for communities to address controversial issues by giving them a human face" (A Fairer World, 2014). Lismore's Living Library was widely reported in our national media - print, radio, television, and internet. There were enquiries from across the nation, with many public libraries wanting to set up their own 'Living Library' for their community. A national organisation was formed and in 2010, the name of the project was changed from Living Libraries Australia to Human Libraries Australia in response to a name change by the international organisation. As in all countries, Australia is overflowing with stories from the fascinating and diverse people that live within. Stories connect us. Human Libraries are a great opportunity for people to sit down, actually meet someone and learn from them. The Human Library is a creative and practical method for helping people to understand and appreciate difference and diversity. It is a simple yet highly effective way for people to build empathy with others and gain understanding.

\section{Human Libraries that engage children and young adults}


Human Libraries have been presented in a variety of ways in Australia and throughout the world, but primarily through Public Libraries and Universities, often as a special one-of event. Initiatives have included:

1. Human Libraries through Public Libraries

2. Human Libraries as Community Events

a. Intergenerational

b. Youth only events

c. Specific groups e.g., 'Young people at risk'

3. Human Libraries in Tertiary Education e.g., TAFE or Universities

4. Human Libraries in schools

\section{The impact of a 'Human Library' on the learning culture of a school}

Through our Human Library, we have now had the opportunity to listen to over forty living books. Our staff and students have been introduced to so many unique and willing members of our college and community who have shared the most amazing stories with us. They have provided wonderful insight into another person's experiences. Our Human Library teaches students how to respect and value others, how to show empathy and gain insight and understanding from all people, many of whom they may not otherwise have had the opportunity to meet. Participating in a Human Library is an excellent way to engage all students in learning.

\section{Resourcing the curriculum}

This exciting initiative has supported and enriched the curriculum by providing students with the opportunity to hear stories about our community and its past; an opportunity to visit countries and experience different cultures through those who have lived or travelled there; an opportunity to learn about a variety of sports and recreational pursuits through people actively participating in them; an opportunity to learn from those with specialist skills; an opportunity to learn from Indigenous students about their culture and an opportunity for students to develop greater awareness of and empathy for people living with disabilities.

\section{Providing an opportunity for people to share their unique story with others}

We all have a 'story'. Events, experiences, people, places, beliefs, customs and cultures shape our lives. They have moulded us into the people we are. As Teacher Librarians, we are very familiar with the phrase 'You can't judge a book by its cover'. It's what's on the inside that is fascinating! Human Libraries are all about people - people sharing stories, their experiences, sharing themselves, their ideas, beliefs and customs, sharing what's important to them. The Human Library provides a creative and practical strategy for doing this by making it possible for students to read a person, instead of a book. Human Libraries are collections of living books that support and encourage diversity, equity and inclusion in our schools. Storytelling is more than just performance or entertainment; sharing living stories through a Human Library can educate, heal, and inspire and change lives. 


\section{Human libraries assist in developing crucial life skills}

The role of a Teacher Librarian continues to change in the $21^{\text {st }}$ century. Students require new skills to work and live productively in our ever-changing global community. McCrindle (2021) suggests some of the crucial transferable skills necessary for Generation Alpha, those born between 2010 and 2024, are: teamwork, resilience, insight, empathy, leadership, the ability to embrace change, emotional and cultural intelligence, personal motivation, the ability to learn and communication skills to enable them to make connections now and in the future. As teachers we need to give our students the skills and competencies that will enable them to thrive. "People who have read our Human Books tell us that the Human Library gives people a window into another world; fun, laughter, knowledge, understanding and tolerance; and a wonderful insight into another person's experiences" (Watson, 2018). It gives students time to think about how they would respond in a similar situation.

Through Human Libraries students learn social skills and widen their understanding of others by:

- becoming connected with diverse members of the community

- learning from real life stories

- meeting people from outside their own circles

Active listening is one of the most effective relationship and communication skills we can develop. It involves listening with our full attention and, importantly, sending non-verbal and verbal signals that we are listening. These signals show the person that we are interested in, care about and respect them (King, 2016). Telling your story is an important skill; listening to others' stories is a lifelong process of understanding yourself and others.

\section{Supporting, encouraging and enriching wellbeing}

McCrindle \& Fell (2021) highlight the importance of having authentic social connections in our lives in order to have a greater ability to flourish and achieve true wellbeing. Human Libraries provide the opportunity for our students to form these connections.

Dr. Helen Street (2018) suggests that student wellbeing needs to be contextual, the belonging and engagement that arise from meaningful connection to a healthy social context. Human Libraries support and promote healthy social norms including being honest and trustworthy and being respectful to others. Healthy social norms need to be actively and openly nurtured within the school community and a Human Library connected to the School Library is the perfect place for this to begin.

Dr Margaret Merga (2020) explores how school libraries may support student wellbeing by operating as safe spaces for young people, promoting and resourcing mental health and wellbeing initiatives, and supporting and promoting bibliotherapeutic practices and reading for pleasure. A Human Library offers a comfortable, safe space where participants can listen and 
learn about other people and their stories in open, frank and respectful interactions. Sharing stories truthfully builds both trust and respect, supporting student wellbeing.

Enabling students to make a valuable contribution to their community

Our 'Human Library' provides a welcoming environment in which participants learn about individuals in their community. It provides an opportunity for all involved to interact, communicate and share with each other in a very special way. Community building is at the very essence of this initiative. It's bringing our community together!

Human Libraries promote increased understanding between generations. Human Libraries offer students who are 'readers' and who are 'living books' opportunities for growth. Students have the opportunity to meet 'living books' of diverse ages and gain insight into their lives and how they think. Older adults get a chance to meet with children and young people, and this helps them face their own prejudices, fears and curiosity about this new generation.

It also creates opportunities for students who are 'living books' to make friends with each other, increasing their understanding of each other's often very different lifestyles through a common experience.

\section{Providing positive role models for students}

The feedback we keep hearing from our students over and over again is how the living books inspire them. They get to talk to people who are living proof that you can survive difficult experiences and learn and grow. The important message students often leave with is, 'if they can do it, then so can I'. Our living books have become positive models for our students, encouraging them to "face the future with a yearn to learn, build on their individual strengths, overcome trials courageously, try new experiences, develop abilities and face the future with a growth mindset" (Dweck, 2012).

\section{Encouraging diversity, equity and inclusion}

It is now more important than ever that we engage in intentional and sustained action to advocate for and advance diversity, equity, and inclusion in our schools. Through a Human Library, students are provided with the perfect space to ask difficult questions of living books, things they may have always wanted to know but never had the opportunity to ask. As students listen to living books, their view on life broadens and they begin to reflect on their own learning and the value it has for them as individuals. This reflective process enables them to grow and flourish. (Seligman, 2013). They are often inspired to share this knowledge with their peers, teachers and family. Together we are building a stronger community with a growing respect for diversity, equity and inclusion. 
A successful education today, is one that helps students to adapt to our rapidly changing times, "not only to partake in meaningful work throughout their life but to thrive as active and global citizens in a changing world" (McCrindle \& Fell, 2020). Broadening our students' experiences by participating in a Human Library, listening to others and seeing the world through the eyes of others, helps students appreciate different points of view, gain awareness of differences, develop empathy and understanding and helps reduce negative stereotypes and tensions between young people. To truly thrive as global citizens our students must develop cultural understanding. The Human Library challenges stereotypes and prejudices through dialogue.

\section{Establishing a Human Library in your school}

Developing a Human Library and inviting living books to share their 'real' stories with students provides them with the opportunity to connect with different kinds of people in the community, develop strong communication skills, be inspired by and appreciate others and encourages them to inquire, explore and learn.

We have enthusiastically undertaken this exciting new initiative in our large K-12 school and it has now been successfully operating for three years. There are many ways a 'Human Library' can be introduced into a school. When establishing a Human Library in your school the following points need to be considered:

1. Sharing the vision

This should include crucial discussions with the Principal and School Executive, sharing the initiative with key stakeholders, providing relevant information and establishing a strategic plan.

2. Deciding on the event format

Plan and develop the approach that best suits the students and organisation in your school. Our Human Library operates one lunchtime each week. Living books share their stories with Primary students followed by Secondary students. This allows the living book the opportunity to pitch their presentation to a specific age group and make discussion more relevant.

3. Identifying a theme for the Human Library

We have established themes within the library as a focal point throughout the year. Our interactive displays, literature promotion, research and our Human Library are all linked directly to these themes. Some of our themes have been: Our Indigenous People, My childhood home, Exciting Recreational Pursuits, Overcomers and Oh the Places we've seen!

4. Locating, selecting and preparing living books

When planning a Human Library, ideas for living books are gathered from across the school community, from staff, students, parents and community members. All suggestions are carefully reviewed, and people approached accordingly. Word of mouth works well to find people who could be living books. Many of our living 
books have come from recommendations made by staff, students and parents. Utilise contacts within your own school community and approach others who have networks in the wider community for help in recruiting people willing to share their stories. Groups to approach could include arts, environment and recreational organisations, council community service and volunteer teams, community clubs, religious and church groups, disability groups, neighbourhood centres, youth organisations, seniors' groups, people from diverse cultural and linguistic backgrounds, schools, TAFEs, adult community colleges and universities. Clear communication of the concept, the organisation, expectations and guidelines are crucial in preparing living books and participants for the event.

\section{Promotion}

Our 'Human Library' is advertised widely, and students are invited to come and listen to the living book in the Library during their lunchtime. Holding the Human Library at a regular time and then advertising in assemblies on the day, reminds keen students and maintains consistency. The Human Library is also advertised on the digital screen in the library, through posters strategically placed around the College and via email to all staff on the day. Staff are also encouraged to attend to show their support, and experience the Human Library for themselves.

\section{Organisation}

A Human Library offers an organised space with a set of simple rules that make it possible for students to listen carefully to others, ask anything they want and to learn from different people. In a school setting, the responsibility of the living book is to prepare their talk, share their special story, pitch it in a way that students will understand, show some interesting things related to their content and be willing to interact with the students and answer their questions. The responsibility of the students is to sit quietly, actively listen, show respect by not interrupting during the story and think of some good questions to ask. Thanking living books for their contribution in front of the students at the end of the session, reinforces the importance of expressing gratitude and appreciation for each individual.

\section{Reflection and Evaluation}

Reflection is the important part of learning. Reflecting on experiences helps you become an active learner by thinking about thoughts and ideas, asking questions and discovering things you had not considered before. By participating in a Human Library and listening to the real stories of others, students are often fascinated and challenged by the knowledge and experiences of living books. This can lead to affirming or reassessing their own values, preferences and biases. Evaluation of the impact of a Human Library can be done through observations, discussions with living books and the students, short surveys and even journaling. Photos and videos provide actual recordings that are useful for reflection. Staff members can also contribute valuable insight and information too. 


\section{The changing face of Human Libraries}

As a result of the COVID-19 pandemic, technology and screens have become more integrated in our lives, education has been delivered more online, there is a deep desire to travel and explore the world, there are impacts on mental health and wellbeing, and many of our students feel more reserved about face-to-face interaction. Despite the pandemic and the upheaval caused in our lives, our students still have "the same intrinsic human needs as we have: to be accepted, to belong and to be part of a community" (McCrindle \& Fell, 2021 p. 61). It is interesting to note, that the longer term impact on our students is predicted to include the following in the foreseeable future: technology will remain integrated in their lives, they will appreciate the things that were lost in the pandemic - interpersonal relationships, seeing their friends and face to face communication with others, they will value family time more as it has become a regular and important part of their lives and they will want to keep some of the new hobbies adopted during COVID-19 such as board games, playing cards and cooking (McCrindle \& Fell, 2021). As a result of our changing world, different ways of presenting a Human Library are now emerging. The challenge will always be: how do we present a Human Library for our students in these changing times, and still continue to encourage the interpersonal connection, social interaction, face to face contact and the development of active listening skills that we appreciate are, and will be, so vitally important to help students flourish in the future?

In 2020, a new study was undertaken on the impact of the Human Library as an online event. Danish research consultancy, Analyse \& Tal, was commissioned by Z Zurich Foundation to conduct a qualitative study to investigate the impact of the Human Library. The study was based on three virtual events held for 200 Zurich Insurance Group employees from different regions of the world. A group of participants who took part as Readers in September 2020 were interviewed before the events and again three months later. The research concluded that Readers found the format of the event to be both surprising and refreshing and inspired them to reflect on their own biases.

This small impact study has provided some exciting evidence that the Human Library has a lasting positive impact on those who attend our events, and we are thrilled to see it inspire our Partners to strengthen their commitment to diversity, equity and inclusion. (Arne-Skidmore, 2021)

Since Covid-19, the Human Library has continued its work virtually in some settings, allowing living books from all over the world to continue to connect with readers.

\section{Conclusion}

As Teacher Librarians, we can have a significant impact on the learning cultures of our schools when we start to build bridges by opening up our school libraries to, not only print and digital resources, but also the lived experiences, the people stories, the living books that exist in the communities we serve. Listening to one another strengthens our social and emotional muscles 
and helps us build powerful interpersonal connections. There are a myriad of ways a Human Library can be used to help build a strong community, support the curriculum, help students to develop interpersonal skills and inspire them to inquire, learn and grow. With a bit of imagination, clever researching, the use of innovative technology, and connection with the right people in our communities, we can all build a wonderful bank of living books to resource our curriculum, help students develop crucial life skills, provide positive role models, inspire our students and help them flourish!

\section{References}

Abergel, R., A. Rothemund, G. Titley \& P. Wootsch. (2005). Don't Judge a Book by its Cover? The Living Library Organiser's Guide. Human Library Organisation. http://humanlibrary.org/guides-for-organisers.html.

Arne-Skidmore, E. (2021). Human Library impact study. Human Library. https://humanlibrary.org/new-study-on-the-impact-of-the-human-library/

Dreher, T., \& J. Mowbray. (2012). The power of one on one: Human Libraries and the challenges of antiracism work. UTS ePress https://opus.lib.uts.edu.au/handle/10453/19829

Dweck, C. (2012). Mindset: Changing the way you think to fulfil your potential. London: Little, Brown Book Group.

Hobart Human Library. (2014). Hobart Human Library history. A Fairer World. www.afairerworld.org/hhl/

King, V. (2016). 10 keys to happier living: A practical handbook for happiness. London: Headline Publishing Group.

Kinsley, L. (2009). Lismore's Living Library: Connecting communities through conversation. Australasian Public Libraries and Information Services, 22(1): 20-25.

McCrindle, M. \& Fell, A. (2021) Generation Alpha: Understanding our children and helping them thrive. Sydney: Hachette Australia.

McCrindle, M. \& Fell, A.(2020). Work wellbeing: Leading thriving teams in rapidly changing times. Summerhill, NSW, Australia: Rockpool Publishing.

Merga, M. (2020). How can school libraries support student wellbeing? Evidence and implications for further research. Journal of Library Administration. 60(6), 660-673. DOI: 10.1080/01930826.2020.1773718

Seligman, M.E.P. (2013). Flourish: A visionary new understanding of happiness and well-being. Miami: Atria Books.

Street, H. (2018) Contextual wellbeing:Creating positive schools from the inside out. Sisters, OR: Wise Solutions.

Watson, G. (2018). Human Library: Unjudge Someone. Human Library Australia. https://www.humanlibraryaus.org/ 
Watson, G. (2015). You shouldn't have to suffer for being who you are: An Examination of the Human Library Strategy for Challenging Prejudice and Increasing Respect for Difference. [Doctoral Dissertation, Curtin University, Perth, Australia]. https://espace.curtin.edu.au/bitstream/handle/20.500.11937/1344/234254_Watson\%20201 5.pdf? sequence $=2 \&$ is Allowed $=y$ 